It is shown that in the existing models of the solar cell, assumptions were made about the ideally smooth surface topography, which had a significant impact on the calculation of the output parameters. It is proposed to take into account the real working area of the receiving surface of the solar cell to improve the accuracy, linearity and stability of the current-voltage characteristics. A geometric model of the structure of the receiving surface of a solar cell has been developed, which describes and takes into account geometric changes in the structure of a semiconductor conducting layer, in the presence of damaging defects in the form of local inhomogeneities, micropores and macrocracks. It was found that the receiving surface with damaging defects is a porous inhomogeneous structure and has fractal properties: self-similarity, invariance, scalability. It is proposed to determine the real working area, to use the method of the theory of fractal geometry and, as an effective quantitative parameter for assessing the change in fractal structure, to choose the value of the fractal dimension. The obtained analytical expressions for the improved model establish the relationship between the output parameters and determine the degree of filling of the current-voltage characteristic for the output power and efficiency. The computational experiment showed that the real area can be much less than the geometric area of the topological relief and is quantitatively related to the change in fractal dimension in the range from 2.31 to 2.63. The obtained data on the real area, when solving analytical expressions for the solar cell model, play an important role in ensuring the stability and linearity of the current-voltage characteristic, increasing its accuracy up to $5 \%$

Keywords: solar cell model, sensing surface of a photoelectric converter, fractal dimension of the structure

Received date 03.05.2021 Accepted date 07.06.2021 Published date 30.06.2021
UDC 621.311 .2

DOI: $10.15587 / 1729-4061.2021 .235882$

\section{DEVELOPMENT OF A SOLAR ELEMENT MODEL USING THE METHOD OF FRACTAL GEOMETRY THEORY}

\author{
Pavlo Budanov \\ $\mathrm{PhD}$, Associate Professor* \\ I hor Kyrysov \\ Senior Lecturer* \\ Kostiantyn Brovko \\ Corresponding author \\ $\mathrm{PhD}$, Associate Professor
}

Department of Integrated Electric Technologies and Processes Kharkiv Petro Vasylenko National Technical University of Agriculture Alchevskih str., 44, Kharkiv, Ukraine, 61002

E-mail: brovkokonstantin@gmail.com

D m y tro Rudenko $\mathrm{PhD*}$

Pavlo Vasiuchenko $\mathrm{PhD}$, Associate Professor*

Andri i Nosyk

$\mathrm{PhD}$, Senior Researcher

Department of Multimedia Information Technologies and Systems National Technical University "Kharkiv Polytechnic Institute"

Kyrpychova str., 2, Kharkiv, Ukraine, 61002

*Department of Physics, Electrical Engineering and Power Engineering

Ukrainian Engineering Pedagogics Academy Universitetska str., 16, Kharkiv, Ukraine, 61003

\section{Introduction}

With long-term operation of solar panels (SP) and batteries, there is a significant decrease in their performance due to the deterioration of the main parameters: efficiency (efficiency) and output power (OP) [1, 2].

Thus, according to [3], about $90 \%$ of the SP market is made up of crystalline silicon SPs, which lose from $10 \%$ to $40 \%$ of their output power in the first two years of operation.

Therefore, it is necessary to take into account such external factors that affect the SP performance, such as normal degradation of the SP over time, a decrease in power due to excessive heating of panels or their shading, etc. [4]. The influence of these and other factors may vary depending on the season, geographic location, installation method, azimuth and slope of the SP [5]. The experience of the SP operation shows that in real conditions, the SP will generate about $75 \ldots 85 \%$ of its peak capacity specified by the manufacturer. For example, a joint venture with a power of $100 \mathrm{~W}$, located at an optimal angle and oriented to the south, will produce an average of $75 \ldots 85 \mathrm{~W}$ in summer, depending on the installation method. Therefore, when designing a solar power plant and assembling solar panels, it is necessary to take into account the full peak power from SP and efficiency.

To achieve high values of power and efficiency in the development of solar cells, a number of factors should be taken into account that affect the conversion efficiency of sunlight. This includes, first of all, the interference of waves when reflected from the receiving surface of the structure of the semiconductor layer of the solar cell, which causes ohmic losses caused by currents flowing in the structure in the lateral direction. This leads to the appearance of interference phenomena and multiple re-reflection of the light wave in the structure of solar cells, which have a significant effect on their characteristics. This can lead to a significant reflection of light or a low collection coefficient, and, consequently, to a low photocurrent and low efficiency of the solar cell. Also, the power and efficiency are influenced by the type of illumi- 
nation distribution over the sensing surface of the solar cell, which leads to inhomogeneity of ohmic losses in the depth of the structure of the semiconductor layer of the solar cell. All of the above factors show the influence of the state of the relief of the receiving surface on the efficiency of semiconductor solar cells, i.e., on the change in power and efficiency.

Therefore, the development of an improved model that makes it possible to predict the current-voltage characteristic with high accuracy on the basis of the known structure of the solar cell of its design and the characteristics of the incident solar radiation is an urgent task. Such a model will make it possible to simultaneously quantitatively describe the most important processes leading to a decrease in the power and efficiency of the solar cell, and, consequently, to optimize the designs of existing and newly developed solar cells, taking into account the area of the receiving surface.

\section{Literature review and problem statement}

SP power changes depending on the illumination and is almost directly proportional to its value [6]. However, at a certain value of illumination, SP can stop production. For example, for crystalline SPs it is approximately $150 \ldots 200 \mathrm{~W} / \mathrm{m}^{2}$, and for amorphous ones - about $100 \mathrm{~W} / \mathrm{m}^{2}$.

Also, the SP power depends on its temperature and usually drops when it rises. A typical temperature coefficient for crystalline SP is $0.45 \% \mathrm{~K}$ (i.e., with an increase in the SP temperature for each degree, its production decreases by $0.45 \%)$ [7].

Analysis of the problem of deterioration of the SP parameters showed that it is determined by the instability of the output parameters of solar cells (SC) or photoelectric converters (PVC), from which the SP is assembled. This can be caused by the following factors [8]: low quality materials and their production; the degree of panel sealing and the quality of the protective properties of the film, etc.

More serious consequences during the SP operation are caused by the occurrence of damaging defects (chips, microcracks, macropores, local inhomogeneities) on the receiving surface of the semiconductor layer (SSL) of the PVC, which lead to an increase in the internal resistance [9].

The reasons for the appearance of such damaging defects on the SC surface may initially differ and have a different nature, but they all significantly affect the internal structure of the PVC SSL. In turn, a change in the PVC SSL structure cause a deviation of the established internal parameters (noload voltage, short-circuit current, internal resistance) and, therefore, affect the output power and efficiency of the SC.

Therefore, the study and modeling of physical processes on the PVC SSL surface relief, in which damage and destruction of the semiconductor structure of the PVC occurs, is an urgent problem faced by the SP manufacturers and consumers.

In the SC development, models are mainly used [10,11], which allow displaying a family of current-voltage (CVC) and volt-watt (VWC) characteristics, depending on the level of solar radiation intensity and temperature. However, in such models [12,13], to describe the main parameters of the $\mathrm{PVC}$, quite often, numerous restrictions and assumptions are used with respect to the actual PVC SSL surface The consequences of these restrictions and assumptions, only with a certain degree of approximation, are also observed in the deviations obtained for the values of the CVC and VWC characteristics of the PVC.
In addition, the low quality and surface defects of the PVC SSL have a significant effect on one of the main parameters - the fill factor of the CVC, which can be used to judge the PVC quality. It is known [14] that typical high-quality, commercially available thin-film PVCs have a CVC fill factor of more than 0.7 , and defective ones from 0.4 to 0.65 . Consequently, the lower the value of the fill factor of the $\mathrm{CVC}$, the greater the losses in the thin-film PVC due to the internal resistance of the semiconductor layer of the PVC.

Thus, the above analysis showed that, due to defects on the PVC SSL surface, losses of solar energy can occur, which leads to nonlinearity and instability of the CVC and VWC. At the same time, the value of the output power and efficiency can be significantly reduced, in contrast to the values set by the SC manufacturer.

Consequently, in the models for calculating the PVC parameters, when simulating the physical processes occurring on the surface and in the PVC SSL structure, it is necessary to take into account both the geometric surface area and with damaging defects. It is known [15-17] that such surfaces with damaging defects have an inhomogeneous and porous structure that possesses fractal properties of self-similarity and scalability and can be characterized by a quantitative value - fractal dimension [18]. Therefore, in the work, to determine and calculate the real actual perceiving surface of the PVC SSL, it is proposed to use the computing apparatus of fractal geometry.

The use of a fractal approach to the study of physical processes in the structure of the semiconductor layer of PVC will make it possible to obtain the dependences of the increments of the geometric area of the damaged receiving surface on the change in the value of the fractal dimension at a certain interval.

It should be noted that the problem of ensuring the minimum operating power and efficiency of the PVC remains unresolved, with a minimum illumination in various temperature ranges. Therefore, the improvement of the known models of solar cells, based on taking into account the real value of the working area of the damaged receiving surface of the semiconductor layer, which affects the installed output power and the efficiency of the solar cell, is an urgent problem. Thus, the relevance of the chosen direction of research lies in the study of processes in the PVC SSL structure, under the influence of damaging defects of the receiving surface, affecting the active area, when calculating the output parameters of the PVC model.

In [19], the problem of increasing the efficiency of converting solar radiation energy into electricity by solar photovoltaic cells is considered. It is shown that the efficiency of photoelectric conversion is determined by the light CVC of the solar cell, the shape of which depends on a number of parameters: series and parallel (shunting) resistances, diode saturation current density, diode coefficient, and some others. The importance of the task of monitoring and optimizing these parameters in the SC production is noted, which requires the creation of a system for monitoring the characteristics of solar cells and improving the methods for determining their parameters. Therefore, the paper considers the SC model, which takes into account the relationship between such parameters as: nominal and maximum power; no-load voltage and rated voltage; short-circuit current and rated current.

The considered model makes it possible to calculate the output power and efficiency of SC only on the basis of the 
given input parameters, which are set by the manufacturer. However, in the proposed analytical expressions of the model, restrictions and assumptions are introduced about ideally smooth surfaces, i.e., without surface defects, which can cause errors and deviations in calculating the real output parameters of the SC. Thus, the advantage of the proposed method is the use of a single CVC and the unambiguity of determining the SC parameters, and its disadvantage is the low accuracy of determining the SC parameters at low values of the parallel resistance.

In work [20], a PVC model is proposed for various operating modes, taking into account the influence of only external factors. In the model, analytical relationships are proposed between the output parameters of the PVC (load current, output voltage) and external conditions: the intensity of solar radiation, temperature and irradiance. As a disadvantage of this model, it should be noted that such model parameters as: reverse saturation current, series and parallel shunt resistance, were calculated only on the basis of the passport data of the solar cell. At the same time, the real data, which significantly depend on the state of the surface relief of the PVC SSL were considered in the model with various assumptions and restrictions.

In [21], the results of experimental studies of the output parameters of the SP are presented: no-load voltage, short-circuit current, output power, taking into account illumination and temperature in different climatic and temperature conditions. In addition, the temperature coefficients of the no-load voltage and short-circuit current were estimated. It has been experimentally confirmed that the short-circuit current directly depends on the illumination, and the open-circuit voltage changes insignificantly due to the logarithmic nature of the dependence on the photocurrent parameter. As a disadvantage, it should be noted that the work shows that the temperature coefficients of the open circuit voltage and short circuit current for a solar station are significantly higher than for a solar monocrystalline cell. However, the reasons for this discrepancy and its influence on the value of the output power have not been investigated.

In [22], it is shown that the output power of photovoltaic modules is influenced by various factors, such as partial shading, solar insolation, temperature and configuration of photovoltaic arrays. These factors cause a decrease in the efficiency and reliability of electric power generation in the PVC. The study of the influence of inhomogeneous partial shading on the PVC characteristics has been carried out. Under these conditions, the photovoltaic PVC CVC becomes more complex, with more than one peak. Therefore, it is very important, under these conditions, to calculate the maximum possible power. For this, let's use MATLAB-based modeling of PVC characteristics. As a disadvantage, it should be noted the following: it is shown in the work that under conditions of partial shading, the load current and heat losses decrease, but the reasons for such a decrease from the state of the PVC surface have not been investigated.

In work [23], studies of the efficiency of solar batteries in field conditions were carried out, and it was found that the electric power of a permanently installed solar battery depends on the following external factors:

- changes in the angle of incidence of the sun's rays, due to the daily and seasonal movement of the Sun across the sky for a given latitude of the area;

- changes in the intensity of solar radiation depending on the transparency of the atmosphere and cloudiness;
- daily and seasonal changes in ambient air temperature;

- heating of photoelectric converters with increasing luminous flux.

It is revealed that at a certain illumination, the maximum power take-off $\left(P_{\max }=U_{\max } \cdot I_{\max }\right)$ from the solar battery takes place only if the external load resistance satisfies the ratio: $R_{V n}=U_{\max } / I_{\max }$. It is shown that at a constant load, a change in the illumination of the working surface of the solar battery leads to a mismatch with the external load, and the power take-off will be lower than the maximum possible values. The disadvantage is that for a PEC made of monocrystalline silicon, the relationship between the maximum power, no-load voltage $U_{o c}$ and short-circuit current $I_{s c}$ was established only experimentally. It was approximately $(0.70 \ldots 0.75)$ of the value of the product $\left(U_{o c} \cdot I_{s c}\right)$. It is also shown that the values of $U_{\max }$ and $I_{\max }$ are approximately related to $U_{o c}$ and $I_{s c}: U_{\max } \approx 0.85 U_{o c}, I_{\max } \approx 0.85 I_{s c}$. Whence the inaccurate approximate value of the load resistance was obtained, at which the maximum electric power is dissipated at a given illumination, and is: $R V n \approx 0.85 U_{o c} / 0.85 I_{s c} \approx U_{o c} / I_{s c}$. This approach to calculating the PVC parameters leads to an inaccuracy of the CVC and does not allow one to determine the real PVC efficiency.

In [24], a simulation model was obtained that displays the family of CVC and VWC depending on the intensity of solar radiation, temperature, short-circuit current values, no-load voltage, internal resistance of the SC, and diode parameter. The discrepancy between these simulation results and the technical factory specifications does not exceed $7 \%$. As a disadvantage, it should be noted that the developed model describes the real solar module, only with a certain degree of approximation, taking into account the accepted assumptions. CVC deviations obtained in the simulation from the experimental ones are observed. In the simulation, the following assumptions were made: CVC and VWC were modeled without taking into account the partial shading of the receiving surface of the PVC and without its possible damage. These assumptions make it possible to use only classical analytical expressions for modeling the PVC characteristics. The main reason for the deviations of the CVC and VWC is the difficulty of accurately measuring both the series and shunt resistances and the active area of solar cells.

The work [25] investigates a method for modeling and simulation of photovoltaic solar cells in the MATLAB/ Simulink/Simscape modeling environment. Application of the method makes it possible to take into account the ratio of characteristics in real panels of photovoltaic converters and to determine the influence of various values of solar radiation, taking into account temperature conditions, on the performance of the system. The proposed solution can be applied to construct various variations of photovoltaic panels and determine the initial parameters.

The disadvantages of the developed physical model in the MATLAB/Simulink/Simscape environment, which makes it possible to associate the electrical parameters of photocells with the level of illumination and temperature of the environment, include the lack of consideration of the geometric dimensions of the surface.

The work [26] is devoted to the issues of constructing a mathematical and MATLAB-model of solar cells. Mathematical expressions describing the relationship between the main parameters of a solar cell are given. The advantages of the proposed approach are substantiated, which consist in the fact that shunt and series resistance are added to the simulation model. 
The presented MATLAB-model of a solar battery makes it possible to investigate the current-voltage characteristic of a solar cell when changing various parameters. Using the MATLAB-model, studies of the dependence of the current-voltage characteristic of a solar cell on the series resistance have been carried out. The results of the work can be used to study emergency modes and transients in solar cells. As a disadvantage, it should be noted that the developed model was created for carrying out static analyzes, with a constant fill factor and working area of the receiving surface of the solar battery.

From the analysis of the above scientific publications, it can be seen that the modeling processes in the SP models were carried out with assumptions regarding the receiving surface, which significantly affect the accuracy, nonlinearity and instability of the CVC and VWC. Consequently, this approach introduces significant errors in the calculations of the electrophysical values of the SC and does not make it possible to use, in full measure, the analytical classical expressions for modeling the SC characteristics. In addition, it should be noted that the accuracy of modeling the CVC and VWC depends on the possible technological scatter for each $\mathrm{SC}$. Therefore, the identification of the correspondence between the SC characteristics presented by the manufacturer and the real SC characteristics during its operation, taking into account various external and internal factors affecting the sensing surface of the SC, is an urgent task.

\section{The aim and objectives of research}

The aim of this research is to improve the SC model by applying the fractal method to study the defects of the SC working surface, which affect the increase in the accuracy, linearity and stability of the CVC. This will make it possible to create highly efficient solar power plants that are economically feasible for various solar complexes.

To achieve the aim, the following objectives were set:

- to analyze the external and internal factors causing damaging defects on the SC sensing surface;

- to develop a geometric model of the SC surface, to study the physical processes occurring in the structure of the semiconductor layer, in the presence of damaging defects on the SC sensing surface;

- on the basis of the geometric analysis of the micro- and macro-roughness of the SC surface, theoretically and experimentally substantiate the choice of an effective parameter for assessing the change in its structure - the value of the fractal dimension;

- to include in the structure of the model the micro- and macrostructure of the receiving surface of the semiconductor layer, based on the method of the theory of fractal geometry;

- to carry out a computational experiment to construct $\mathrm{CVC}$ of the receiving surface, and theoretically confirm the influence of the changed geometric characteristics of the surface on the SC parameters.

\section{Materials and methods of research}

4.1. General information about the design and physical processes occurring on the surface of the solar cell

As is known [27-29], the photoelectric effect is manifested in a photovoltaic system that directly converts solar energy into electricity.
The simplest design of PVC or SC, a device for converting solar radiation energy, based on monocrystalline silicon, is shown in Fig. 1. From Fig. 1 it is possible to see that on one side (front) of the $p$ - $n$-junction there is an $n$-layer with a thin metal contact, and on the other side (back) a $p$-layer on which a solid metal contact is applied. When illuminated by a solar cell, the incident electron flux generates non-equilibrium electron-hole pairs. The electrons generated in the $p$-layer approach the $p$ - $n$-junction and are carried away by the existing electric field in it into the $n$-layer. The same happens with holes formed in the $n$-layer, they are transferred to the $p$-layer.

Therefore, the $n$-layer acquires an additional negative charge, and the $p$-layer is positive, therefore, the initial contact potential difference between the $p$ - and $n$-layer of the semiconductor decreases. This entails the appearance of a constant voltage in the external electrical circuit, with the $n$-layer corresponding to the negative pole, and the $p$-layer to the positive.

If a variable load resistance is connected to the $p$ - $n$-junction (Fig. 1), then the direction of the current in it always coincides with the direction of the photocurrent, and the load current itself is equal to the resulting current through the $p$ - $n$-junction. This makes it possible to obtain the equation of the total current (for a unit area of the solar cell).

As is known [30-33], the PVC construction models is based on taking into account the following parameters: output (load current, output power, voltage); external (illumination, temperature, angle of incidence of light), internal (no-load voltage and short-circuit current). For the development of a PVC model, which makes it possible to assess the influence on the output PVC characteristics, both internal $U_{o c}, I_{s c}$ and external factors $(W, T, \alpha)$, an equivalent electric circuit of the PVC is used (Fig. 2).

According to Kirchhoff's law, the ratio of currents in the circuit of the equivalent electrical equivalent circuit (Fig. 2) will be determined by the following expression (1):

$$
I_{N}=I_{F}-I_{D}-I_{R_{S}},
$$

where $I_{N}$ - current in the circuit, A; $I_{F}$ - photocurrent, A; ID - current flowing through the idealized pn junction, A; $I_{D}$ - current through the shunt resistance $R_{s}$, A.

It should be noted that, since the photocurrent $I_{F}$ is directly proportional to the illumination $E$ and increases with an increase in the temperature $T$ of the PVC, it is often, according to [34], determined by the expression (2):

$$
I_{F}=\frac{E}{E_{0}}\left[I_{s c}+k_{I_{S C}}\left(T-T_{0}\right)\right],
$$

where $E$-irradiance, $\mathrm{W} / \mathrm{m}^{2}$;

$$
E_{0}=1000 \frac{\mathrm{W}}{\mathrm{m}^{2}}-\text { irradiance under standard conditions; }
$$

$I_{S C}$ - short-circuit current, A;

$k_{I S c}$ - temperature coefficient of the short-circuit current; $T$ - absolute temperature of the PVC SSL.

From expression (2), it can be seen that the introduced assumption of an ideal smooth surface does not allow taking into account the effect of the total geometric area on the output parameters of the PVC, and, therefore, introduces significant errors in the $\mathrm{CVC}$ construction. 


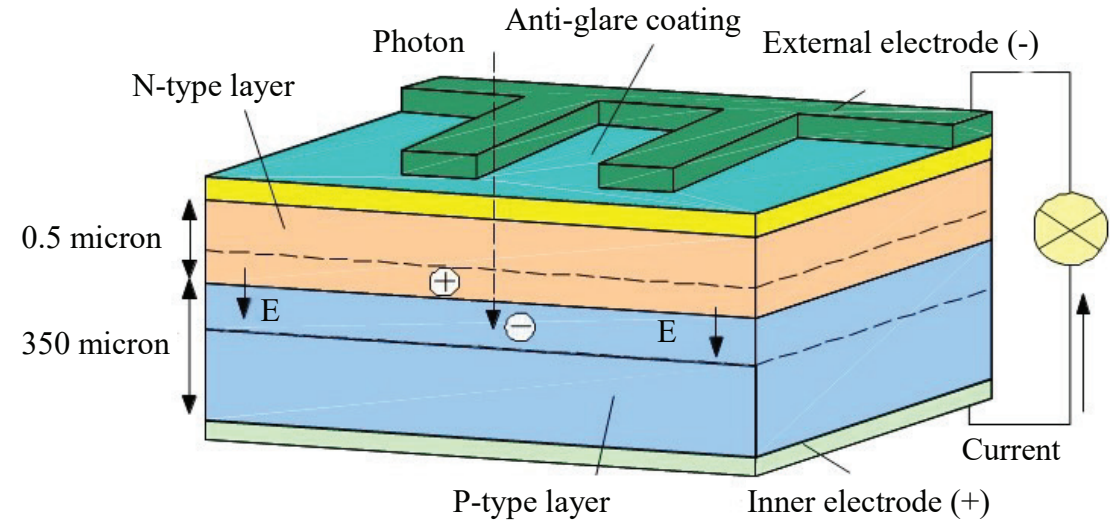

Fig. 1. Photovoltaic converter

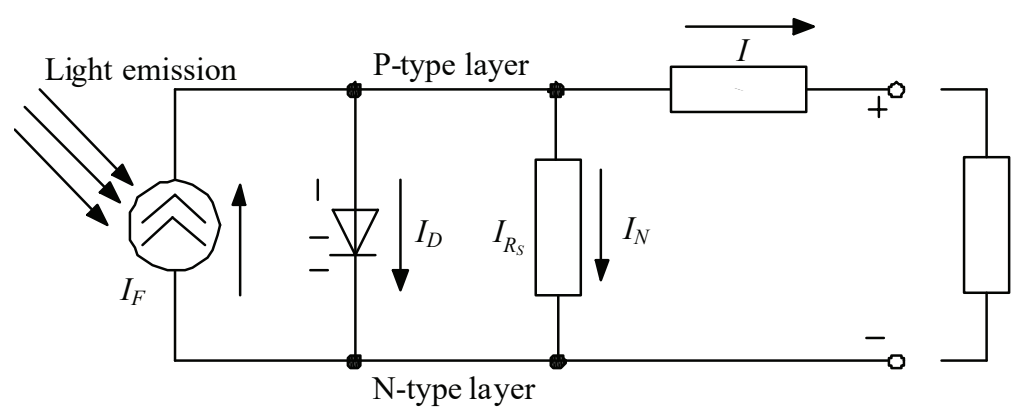

Fig. 2. Equivalent electric circuit of the solar photovoltaic converter

4. 2. Investigation of a model of a solar photovoltaic converter, taking into account the total geometric area

In this work, to study the effect of the properties of a real sensing surface on the PVC output parameters, it was proposed to use expression (3) to determine the photocurrent $\left(I_{F}\right)$, taking into account the total geometric area $\left(S_{\Sigma}\right)$ of the surface PVC SSL:

$$
I_{F}=\frac{F_{o} \cdot e}{h \cdot v} \cdot(1-R) \cdot \eta \cdot K_{c} \cdot S_{\Sigma}
$$

where $F_{0}$ - input luminous flux;

$e$ - electron charge;

$h$ - Planck's constant;

$v$ - frequency of the incident light flux;

$R$-coefficient of reflection of the luminous flux from the front surface;

$\eta$ - coefficient of the reflected light flux of the frontal surface;

$K_{c}$ - integral coefficient of collection of carriers;

$S_{\Sigma}-$ total geometrical area of the receiving PVC SSL surface.

Since a $p$ - $n$ junction is connected in parallel to the current source, the current passing through the diode $I_{D}$ is equal to the expression (4):

$$
I_{D}=I_{r s c}\left[\exp \left(\frac{U}{\varphi_{T}}\right)-1\right]=I_{O N}\left[\exp \left(\frac{e \cdot U}{k \cdot T}\right)-1\right],
$$

where $I_{r s c}$ - the reverse saturation current of the diode;

$U_{V}$ - output voltage;

$\varphi=\frac{k \cdot T}{e}-$ thermal potential;

$k$ - Boltzmann constant;

$T$ - absolute temperature;

$e$ - electron charge.
Then, taking into account (3) and (4), expression (1) can be written as analytical expressions (5) and (6) of the PVC model, connecting the load current $I_{N}$ and the output voltage $U_{N}$, with the total area $S_{\Sigma}$ of the receiving surface:

$$
\begin{aligned}
& I_{N}=\frac{F_{o} \cdot e}{h \cdot v} \cdot(1-R) \cdot \eta \cdot K_{c} \cdot S_{\Sigma}- \\
& -I_{O N}\left[\exp \left(\frac{e \cdot\left(U_{V}+I_{N} \cdot R_{p}\right)}{A \cdot k \cdot T}\right)-1\right]- \\
& -\frac{U_{V}+I_{N}}{R_{S}}
\end{aligned}
$$

$$
\begin{aligned}
& U_{N}=\left(\frac{k T}{e}\right) \times \\
& \times \ln \left(\frac{\left[\frac{F_{o} \cdot e}{h \cdot v} \cdot(1-R) \cdot \eta \cdot K_{c} \cdot S_{\Sigma} \cdot\right]-I_{N}}{I_{0}}+1\right),
\end{aligned}
$$

where $A$ - diode coefficient (depending on the current flowing through the pn-junction, the coefficient A can vary from 1 to 2 (diffusion or recombination currents, respectively); $R_{p}-$ series resistance; $R_{S}$ - shunt resistance.

In accordance with equation (5) and (6), in Fig. 3 shows the SC, which is the most important characteristic, since it determines the SC efficiency, as the efficiency of converting solar radiation energy into electricity. The PVC efficiency is defined as the ratio of the power generated by the solar cell to the power of the incident solar radiation. In the work, it is proposed, according to [35], to determine the PVC efficiency by the expression (7):

$$
\eta_{K P D}=\frac{P_{\max }}{P_{p}}=\frac{I_{s c} \cdot U_{o c} \cdot F_{Z}}{P_{p}}=\frac{I_{m} \cdot U_{m}}{P_{p}},
$$

where $I_{m}$ and $U_{m}$ - current and voltage corresponding to the point of greatest power $P_{\max }$, as shown in Fig. 3;

$P_{\max }=U_{o c} \cdot I_{s c} \cdot F_{Z}-$ maximum output power of the solar cell;

$P_{p}$ - power of the radiation incident on the solar cell;

$U_{o c}-$ open circuit voltage;

$F_{Z}=\frac{I_{m} \cdot U_{m}}{I_{s c} \cdot U_{o c}}-$ PVC CVC fill factor.

Due to the fact that the PVC efficiency depends on the shape of its CVC (according to expression (7)), the PVC parameters, included in the CVC equation (5) and (6), determine the PVC efficiency. The construction of CVC in accordance with Eqs. (5) and (6), for various values of the SC parameters, demonstrates that the CVC form significantly depends on the parameters, the exact values of which are necessary to predict the PVC operation. Therefore, in the development and production of SC, it is required to use the method of reliable determination of their parameters, depending on the active receiving surface of the semiconductor layer relief of the PVC. Let's consider the influence of the internal parameters $U_{o c}$ and $I_{s c}$ on the construction of the PVC model.

Open circuit voltage $U_{o c}$ is the maximum voltage generated by the solar cell at zero current (Fig. 3). It is equal to the forward bias corresponding to the change in the voltage 
of the $p$ - $n$ junction when the light current appears. The open circuit voltage of the solar cell changes little with a change in illumination and is determined according to [36,37] by expression (10):

$$
U_{o c}=\varphi_{T} \cdot \ln \left(\frac{I_{F}}{I_{0}}+1\right)=\frac{k T}{e} \cdot \ln \left(\frac{I_{F}}{I_{0}}+1\right),
$$

or taking into account (3), equation (8) will take the form (9), to calculate the open circuit voltage $U_{o c}$, taking into account the total geometric area $S_{\Sigma}$ :

$$
U_{o c}=\frac{k T}{e} \cdot \ln \left(\frac{\frac{F_{o} \cdot e}{h \cdot v} \cdot(1-R) \cdot \eta \cdot K_{c} \cdot S_{\Sigma F E P}}{I_{0}}+1\right) .
$$

Short-circuit current $I_{s c}$ is the current flowing through the SC when the voltage is zero (that is, when the SC is short-circuited) (Fig. 3). It arises as a result of the generation and separation of carriers generated by light. In an ideal SC, subject to moderate resistive losses, it is equal to the light current. Therefore, the short-circuit current can be considered the maximum current that the SC can create. In addition, it is directly proportional to the light intensity, and can, at $I_{S c}=I_{F}$, as shown in $[38,39]$, is determined by expression (10):

$$
I_{s c}=\frac{F_{o} \cdot e}{h \cdot v} \cdot(1-R) \cdot \eta \cdot K_{c} \cdot S_{\Sigma} .
$$

Short-circuit current $I_{s c}$ and open-circuit voltage $U_{o c}$ are the maximum current and voltage that can be obtained from the SC, however, at $I_{s c}$ and $U_{o c}$, the SC power is 0 . The fill factor $F_{z}$ is a parameter that, in combination with the OCV and SCC, determines the maximum power of the SC. Graphically, the fill factor is a measure of the SC squareness and is equal to the maximum area of a rectangle that can be inscribed in the current-voltage curve (Fig. 3,a). The fill factor of the CVC is one of the main parameters by which one can judge the quality of a photovoltaic converter. Typical high quality commercially available solar cells have a CVC fill factor of more than 0.7, i.e., the larger the CVC fill factor, the lower the cell losses due to internal resistance. The graph in Fig. 3, b, curves is shown that have the same values short-circuit current and open-circuit voltage. However, a cell with a lower CVC duty cycle (bottom graph) produces less power at the maximum power point (MPP).
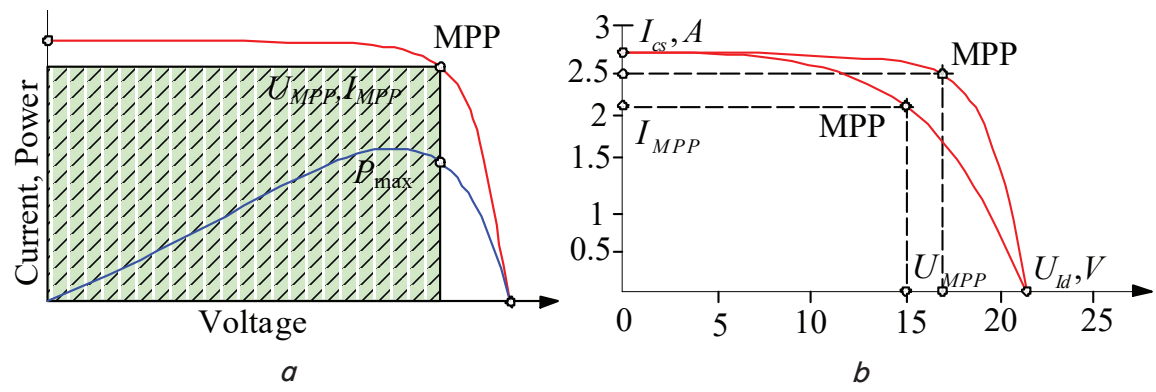

Fig. 3. Current-voltage characteristic of a solar photovoltaic converter: $a$ - current-voltage curve for the duty cycle; $b$-current-voltage curve for different values of the fill factor

To determine the dependence of the PVC efficiency on the total area of the receiving surface of the PVC SSL, in the work, according to [40], the expression (14) was proposed:

$$
\eta_{K P D}=\frac{I_{s c} \cdot U_{o c} \cdot F_{Z}}{E_{c} \cdot S_{\Sigma}}
$$

where $I_{s c}-$ the short-circuit current;

$U_{o c}$ - open circuit voltage;

$E_{c}=1000 \frac{\mathrm{W}}{\mathrm{m}^{2}}-$ density of the solar radiation flux;

$S_{\Sigma}-$ total surface area of the PVC.

From the obtained analytical expressions (2)-(11) of the PVC model, the following conclusions can be drawn:

- dependence of the magnitude of the current is shown, only here are the external factors affecting the PVC surface, i.e. intensity and density of radiation;

- analytical dependences, built taking into account only the geometric topological surface area without a quantitative and qualitative assessment of the real surface, which does not allow constructing the CVC of the solar cell with an accuracy sufficient for engineering calculations;

- in this model, the influence of various conditions on the output characteristics of the PVC is taken into account when the state of the surface changes.

Thus, the analysis of analytical expressions (2)-(11) of the SC model shows that it is necessary to take into account the change in the value of the geometric surface area, which can significantly affect, when calculating the output parameters of the SC. In addition, the analysis of this model shows that when it is applied for modeling and analyzing SC, a number of restrictions are introduced and allowed. This leads to significant, and sometimes undesirable deviations from the CVC of a real solar cell, which distorts the real indicators of the output power and efficiency of the SC.

One of the reasons for such deviations in the CVC is certain difficulties in assessing the quality of the surface relief of the PVC, and in particular the effect of damaging defects on the internal structure of the surface film of the PVC. An analysis of formulas (2)-(11) shows that it is necessary to take into account the change in the value of the geometric area of the receptive surface of the PVC SSL, when damaging defects are exposed to it.

Therefore, the work substantiates the need to include in the main analytical expressions (2)-(11) such an additional parameter as the value of the real area of the perceiving surface, which is proposed to be calculated using the apparatus of fractal geometry.

\section{Results of investigations of the receptive surface of the semiconductor layer relief of a solar cell}

5. 1. Analysis of the causes of damaging defects and their effect on the surface of the solar cell

A review of global manufacturers of solar panels (Jinko Solar, Trina Solar) showed that for efficient and high-quality operation in any operating mode, it is necessary to comply with certain requirements and conditions for the surface layer of a semiconductor:

- optical absorption coefficient of the active layer of the semiconductor must be large enough to ensure the absorp- 
tion of a significant part of the energy of sunlight within the layer thickness;

- electrons and holes generated under illumination should be efficiently collected on contact electrodes on both sides of the active layer;

- solar cell must have a significant barrier height in the semiconductor junction;

- total resistance connected in series with the solar cell (excluding the load resistance) must be small in order to reduce the power losses (Joule heat) during operation;

- structure of the thin film must be uniform throughout the active region of the SC in order to exclude short-circuiting and the influence of shunting resistances on the characteristics of the element.

Consequently, the above requirements and conditions, for the most part, are associated with a change in such geometric parameters as the thickness and area of the active layer of the SC surface. Of particular importance is the uniformity of the relief of the surface film, i.e., the absence of various damaging defects (chips, macro- and microcracks, pores, local inhomogeneities) affecting the internal structure of the SC.

Let's consider and analyze external factors that can cause damaging defects on the sensing surface of the SC.

The manufacturing quality of the solar cell depends on the materials and equipment used in its manufacture, while influencing the shunt and series resistance, noise currents and other parameters.

The quality of the SC soldering affects the possible local overheating of the contact and its burnout.

The quality of the ethylene vinyl acetate (EVA) film affects the aging of crystalline SC, due to wear and cloudiness (therefore, the power loss by the panel will exceed $25 . . .30 \%$ ).

The quality of the panel sealing and the quality of the rear protective film affect the removal of moisture from the inside of the element to the outside. With a poor-quality film, the amount of moisture gets in more than it can get out when heated, and residual moisture accumulates inside the element, destroys the contacts of the elements, which leads to premature failure of the element.

The quality of the aluminum frame affects anodizing and can lead to frame oxidation and corrosion. This defect can lead to accelerated corrosion and metal and premature destruction and SP failure.

Let's especially dwell on the analysis of internal factors, due to which various defects appear in the form of macroand microcracks in the structure of the surface of the semiconductor layer of the SC, which have a significant effect on the parameters during the SC operation [23-25]. Surface defects with macro- and micro-dimensions on the SC surface, which are practically unrecognizable by the human eye, often lead to more serious problems. The reasons for the appearance of microcracks on the SC surface may initially differ. Cell breakage is a common problem faced by both SP manufacturers and operators, before and after installation.

Microcracks on the SC can appear at different stages: during production, transportation/installation, and when the SP is exposed to the atmospheric environment [9]. Various operating environments and natural factors (mechanical and chemical) affecting the SP operation, such as snow, hail, extreme cold, wind and sun, can cause microcracks in the joint venture. Other stress factors can be related to the thermal cycle of the elements, which includes expansion, contraction, and stretching of metal contacts and wire interconnec- tions. The advanced manufacturing techniques applied by individual manufacturers have so far succeeded very well in preventing micro-cracks in the SP caused by environmental factors. However, it is practically impossible to avoid microcracks in the long term, their potential side effects can lead to a serious problem when the SCs are operated in various operating modes. The results of the influence of damaging defects on the PVC SSL structure are manifested in a decrease in the efficiency of the short-circuit cell. Such results are due to mechanical stress or thermal stress. During the production process, microcracks occur mainly during the lamination of the panel, especially when certain films such as EVA with poor moisture resistance are used. In such cases, moisture passes through micro cracks on the front of the laminate and then oxidation of the contact fingers occurs.

Microcracks on the PVC SSL surface of the lead to an increase in the resistance of the element, since electricity follows the path of least resistance [11]. Broken cells ensure that electrons are forced to use alternative (congested) pathways. The presence of microcracks on the SC surface will lead to a decrease in the SC lifetime and will affect the calculations of the return on investment, overall productivity and the possibility of premature replacement of arrays. Replacing damaged single SC is often not suitable due to changes in electrical characteristics over time.

Thus, the above analysis of the main reasons for the appearance of damaging defects on the SC surface showed that this leads to changes in the geometric area of the receiving surface, and will affect the values of the preset factory parameters. In addition, the assumptions about a smooth active receiving surface of the $\mathrm{SC}$ will introduce a significant error in calculating the output parameters, which will affect the accuracy of constructing the $\mathrm{CVC}$ and determining the $\mathrm{SC}$ efficiency.

\section{2. Application of the method of the theory of fractal geometry for the development of a geometric model of the solar cell surface}

During the PVC operation, various external (solar and radiation exposure, temperature) and internal (structural changes in the material) factors act on its surface. As a result of such an impact, various damaging defects can appear on the surface, in the form of local inhomogeneities, micropores and macrocracks, which leads to a change in its geometric topological area $S_{G}$

To consider the influence of damaging defects of the receiving surface of the semiconductor layer on the PVC parameters, studies of the physical processes occurring on the external and internal structure of the PVC surface were carried out. It is known $[15,16]$ that the PVC surface, as well as the metal - semiconductor interface, are not flat. In fact, there is a relief with a rough surface or interface, the relief of which can be determined both by the nature of the processing (chemical-dynamic, plasma-chemical, radiation), and by the method of applying a barrier metal contact (for the metal-semiconductor interface). The presence of damaging defects leads to the further development of the surface relief of the PVC SSL, which can lead to a significant increase in the actual contact area, which can significantly exceed the topological geometric area $S_{G}$. The consequences of this fact, i.e., the influence of such a contact on the PVC parameters, are not always obvious, therefore it is necessary to evaluate the properties of the receiving surface, taking into account the damaging relief defects. Thus, the influence of such de- 
fects leads to the fact that the receiving surface of the PVC SSL has a rough, porous, inhomogeneous relief. As is known from [15-18], such structures have specific fractal properties: self-similarity, invariance, and scalability. Consequently, for the study of the PVC SSL structures, it is proposed to apply the method of the theory of fractal geometry.

Therefore, to determine the real working area $S_{R E A L}$, it is proposed to consider the processes occurring in the structure of the surface semiconductor layer of a PVC, based on the application of the method of the theory of fractal geometry [15-18]. The choice of the fractal method for studying the receptive surface of the $\mathrm{SC}$, in contrast to other known methods, makes it possible to relate the change in the internal structure of the PVC SSL with the input and output parameters of the SC.

From the point of view of fractal theory, the surface area of the PVC can be represented in the form of a structural geometric model shown in Fig. 4. When external and internal factors act on the PVC surface, physical processes occur in its structure, which lead to the formation of defects in the form of: local inhomogeneities, micropores, micro and macrocracks (Fig. 4).
5. 3. Justification of the choice of the parameter for assessing the change in the surface structure of the solar cell - the value of the fractal dimension

In [15-18], it is shown that surfaces with damaging defects are a rough porous inhomogeneous structure, and have specific fractal properties: self-similarity, invariance and scalability and are estimated by the quantitative value of the fractal dimension. As is known [16-18], the value of the fractal dimension $d_{f}$ determines the degree of filling of the Euclidean space of the surface structure with fractal properties.

Then, proceeding from the application of the apparatus of fractal geometry, let's obtain expression (13) for describing the real area $S_{\text {REAL }}$ of the receptive surface of the PVC, which has fractal properties, using the value of the fractal dimension $d_{f}$ :

$$
S_{R E A L}=S_{G} \cdot \alpha^{d-d_{f r}},
$$

where $S_{R E A L}$ - real area of the receptive surface of the PVC with fractal properties;

$d$ - topological Euclidean dimension $\left(d_{1}=1\right.$ for a straight line, $d_{2}=2$ for a plane, $d_{2}=3$ for a volume); $d_{f}$ - fractal dimension of the structure of the PVC SSL surface;

$\alpha$ - dimensionless measuring scale factor satisfying the condition $\alpha<1$.

It is important to note that if the geometric area of the smooth PVC surface exceeds the value of the real area, that is, $S_{G}>S_{R E A L}$, then the condition must be met under which the dimension of the fractal surface exceeds the Euclidean dimension, $d_{2}<d_{f}$ for $d_{2}=2$.

Then, according to [15-18], expression (13) will have the following form (14):

$$
S_{R E A L}=S_{G} \cdot \alpha^{2-d_{f r}} .
$$

The appearance of such surface formations introduces additional geometric increments from various local areas $\left(\Delta S_{M T} ; \Delta S_{M P} ; \Delta S_{M M T} ; \Delta S_{L N}\right)$ over the entire PVC surface, and has a significant effect on the change in the internal structure of the PVC SSL. It should be noted that as a result of this, the photoactive area of the receiving surface decreases by the amount of the sum of all increments $\Delta S_{\Sigma}=\Delta S_{M T}+\Delta S_{M P}+\Delta S_{M M T}+\Delta S_{L}$, and then expression (12) can be written to determine the real area $S_{R E A L}$ of the receptive surface of the PVC:

$$
\begin{aligned}
& S_{R E A L}=S_{G}-\Delta S_{\Sigma}= \\
& =S_{G}-\left(\Delta S_{M T}+\Delta S_{M P}+\Delta S_{M M T}+\Delta S_{L N}\right),
\end{aligned}
$$

where $S_{R E A L}$ - real area of the receptive surfaces of the PVC with damaging defects;

$S_{G}$-geometric area of the topological surface of the PVC;

$\Delta S_{\Sigma}$ - sum of geometric increments of local areas;

$\Delta S_{M T}$ - geometric increment of the local area of the macrocrack;

$\Delta S_{M M T}$ - geometric increment of the local area of the microcrack;

$\Delta S_{M P}$ - geometric increment of the local area of the micropore;

$\Delta S_{L N}-$ geometric increment of the local area of the heterogeneity.
From expression (14), it follows that when $d_{f}=d=2$ (i.e., when the fractal and topological dimensions are equal), the equality $S_{G}=S_{R E A L}$ is confirmed, and then draw a conclusion about the non-fractality of the surface. If the receiving surface is a fractal object and, therefore, its area $S_{G}>S_{R E A L}$, then, as follows from (13), the following condition $2<d_{f}<3$ should be satisfied for the fractal dimension. This relationship makes it possible to give a more rigorous definition of the fractal dimension as a critical dimension.

It can also be seen from expression (14) that the dimensionless parameter $\alpha$ can be used as a characteristic of the measuring scale for a given area. For the fractal surface of a solar PVC, according to expression (14), a certain value of the scale dimensionless coefficient $\alpha$ corresponds to a certain value of the area of the fractal surface.

Having constructed the dependence $\ln \frac{S_{R E A L}}{S_{G}}$ on $\ln \frac{1}{\alpha}$ by the angle of inclination of its linear section, it is possible to determine the theoretical value of the fractal dimension $d_{f}$, as shown in Fig. 5 .

From Fig. 5, $a$, it can be seen that with a smooth topological surface (high quality, close to ideal), that is, when $\ln \frac{S_{R E A L}}{S_{G}} \approx 1$, and therefore at $d=2 \approx d_{f}$, there is practically no angle of inclination. The insignificant angle of inclination 
is explained by the presence on the PVC surface, local inhomogeneities and pores with a size of $\alpha<3 \ldots 5 \mu \mathrm{m}$, obtained during manufacture, and further, during the computational experiment, is a condition for choosing a measuring scale.

Fig. $5, b$, it can be seen that for $d_{f}>d_{2}$, the angle of inclination of the linear section depends on the change in the value of the real area of the fractal surface, namely, with its decrease, the fractal dimension tends to the Euclidean dimension of the volumetric space $d_{f} \rightarrow d_{3}=3$ of a semiconductor layer with a thickness of $\delta$.
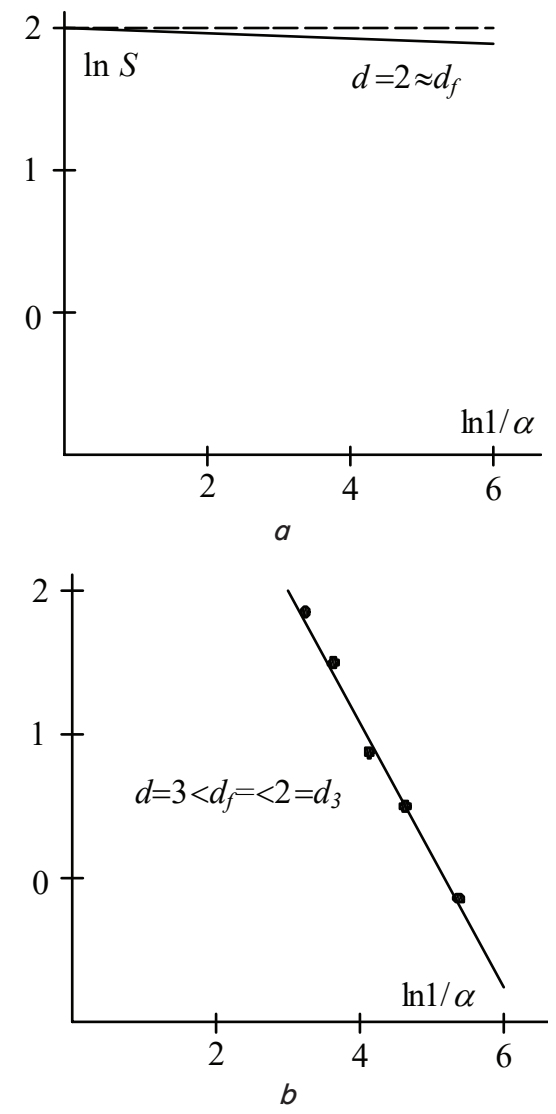

Fig. 5. Determination of the value of the fractal dimension of the surface of the semiconductor layer of the PVC: $a-$ for the geometric surface $S_{G}$ at $d=d_{f} ; b-$ for the real area of the fractal surface $S_{R E A L}$ at $2<d_{f}<3$

Consequently, when taking into account the influence of damaging factors on the PVC surface, it is necessary to take into account both the change in the surface relief and the internal volumetric structure of the semiconductor layer.

Then, proceeding from this, the geometric and, accordingly, the fractal volume of the PVC SSL structure can be determined by the expression (15), (16):

$$
\begin{aligned}
& V_{G}=S_{G} \cdot \delta ; \\
& V_{F}=V_{G} \cdot \alpha^{d_{3}-d_{f}}=S_{G} \cdot \delta \cdot\left(\alpha^{d_{3}-d_{f}}\right),
\end{aligned}
$$

where $V_{G}$-volume of the geometric structure of the semiconductors of the PVC layer;

$V_{F}$ - volume of the real structure of semiconductors of the PVC layer with fractal properties;

$\delta_{f}$-thickness of the PVC SSL fractal surface;

$d_{f}$ - fractal dimension of the internal structure of semiconductors of the PVC layer $2<d_{f}<3$; $d_{3}$ - Euclidean dimension for the volumetric structure of semiconductors of the PVC layer $d_{3}=3$;

$\alpha$-measuring scale dimensionless coefficient, satisfying the condition $\alpha<1$.

Then the increment of the internal structure, taking into account the fractal properties, will be determined by the expression (17):

$$
\begin{aligned}
& \Delta V=V_{G}-V_{F}=S_{G} \cdot \delta_{f}- \\
& -S_{G} \cdot \delta_{f} \cdot\left(\alpha^{d_{3}-d_{f}}\right)=S_{G} \cdot \delta_{f} \cdot\left(1-\alpha^{3-d_{f}}\right),
\end{aligned}
$$

where $V_{F}$ - fractal volume of the PVC SSL structure; $S_{F}$-area of the PVC fractal surface;

From expression (17) it is possible to see that the change in the structure of the receiving surface of the PVC occurs both on the horizontal surface relief with a power exponent $2-d_{f}$, and vertically along the thickness $\delta_{f}$ of the entire volume with an exponent $3-d_{f}$.

From expression (17), it is possible to see that at $d_{f}=3$, the power exponent is $d_{3}-d_{f} \rightarrow 0$, i.e., the increment is $\Delta V \rightarrow 0$. Therefore, when calculating the main parameters of the PVC, it is necessary to take into account the real changes in the volumetric real structure of the semiconductor layer of the PVC, by multiplying the area of the geometric area $S_{G}$ by the indicator $1-\alpha^{3-d_{f}}(18)$ :

$$
S_{R E A L}=S_{G}\left(1-\alpha^{d_{3}-d_{f}}\right)=S_{G}\left(1-\alpha^{3-d_{f}}\right) .
$$

Then, taking into account the above, it is proposed in the work to consider the real area of the $S_{R E A L}$ PVC as a change in the geometric area $S_{G}$ of the fractal surface in a power-law dependence on the change in the value of the fractal dimension of the structure in the range $2<d_{f}<3$.

5. 4. The structure of the model, taking into account the micro- and macrostructure of the receiving surface of the semiconductor layer

On the basis of the above substantiations, analytical expressions were proposed that determine an improved model of the PVC operation, taking into account the value of the real area of the receiving surface of the $\mathrm{S}_{\mathrm{REAL}} \mathrm{PVC}$, calculated using the apparatus of fractal geometry.

Then, substituting expression (18) into (3), (5), (6), (9)-(11), let's obtain analytical expressions for the improved model of the PVC, taking into account the real area of the receiving surface of the semiconductor layer of the PVC:

- for the value of the photocurrent $I_{F}$ :

$$
I_{F}=\frac{F_{o} \cdot e}{h \cdot v} \cdot(1-R) \cdot \eta \cdot K_{c} \cdot S_{G} \cdot\left(1-\alpha^{3-d_{f}}\right)
$$

- for open circuit voltage $U_{o c f}$ :

$$
U_{X X f}=\frac{k T}{e} \cdot \ln \left[\frac{F_{0}(1-R) \cdot \eta \cdot K_{C} \cdot S_{G} \cdot\left(1-\alpha^{3-d_{f}}\right)}{h v I_{0}}\right]+1 ;
$$

- for short-circuit current $I_{s c}$ :

$$
I_{s c}=\frac{F_{o} \cdot e}{h \cdot v} \cdot(1-R) \cdot \eta \cdot K_{c} \cdot S_{G} \cdot\left(1-\alpha^{3-d_{f}}\right) ;
$$

- for load current $I_{N}$ : 


$$
\begin{aligned}
& I_{N}=\frac{F_{o} \cdot e}{h \cdot v} \cdot(1-R) \cdot \eta \cdot K_{c} \cdot S_{G} \cdot\left(1-\alpha^{3-d_{f}}\right)- \\
& -I_{O N}\left[\exp \left(\frac{e \cdot\left(U_{N}+I_{N} \cdot R_{p}\right)}{A \cdot k \cdot T}\right)-1\right]-\frac{U_{N}+I_{N}}{R_{S}} ;
\end{aligned}
$$

- for output voltage $U_{N}$ :

$$
\begin{aligned}
& U_{N}=\left(\frac{k T}{e}\right) \times \\
& \times \ln \left(\frac{\left[\frac{F_{o} \cdot e}{h \cdot v} \cdot(1-R) \cdot \eta \cdot K_{c} \cdot S_{G} \cdot\left(1-\alpha^{3-d_{f}}\right)\right]-I_{N}}{I_{0}}+1\right) ;
\end{aligned}
$$

- for maximum power output $P_{\max }$ :

$$
\begin{aligned}
& P_{\max }=F_{Z} \frac{k T}{e} \cdot \ln \left[\frac{F_{0}(1-R) \cdot \eta \cdot K_{C} \cdot S_{G} \cdot\left(1-\alpha^{3-d_{f}}\right)}{h v I_{0}}\right] \times \\
& \times\left[\frac{F_{o} \cdot e}{h \cdot v} \cdot(1-R) \cdot \eta \cdot K_{c} \cdot S_{G} \cdot\left(1-\alpha^{3-d_{f}}\right)\right] .
\end{aligned}
$$

For a receiving surface with damaging defects, the PVC efficiency $\eta_{\text {eff }}$ will be determined by the expression (28):

$$
\begin{aligned}
& \eta_{e f f}= \\
& =\frac{\left[\frac{F_{o} \cdot e}{h \cdot v} \cdot(1-R) \cdot \eta \cdot K_{c}\right] \cdot \frac{k T}{e} \cdot \ln \left[\frac{F_{0}(1-R) \cdot \eta \cdot K_{C} \cdot S_{G} \cdot\left(1-\alpha^{3-d_{f}}\right)}{h v I_{0}}\right]+1}{E_{c}} .
\end{aligned}
$$

From expression (25), it follows that the PVC efficiency $\eta_{\text {eff }}$ depends both on the light radiation and temperature, and on the change in the geometric area of the receiving surface of the PVC with damaging defects. In this case, the power-law dependence of the real area of the receiving surface with damaging defects on the change in the value of the fractal dimension in the bulk structure over the entire thickness of the PVC SSL is taken into account.

Thus, analytical expressions (19) $-(25)$ of the improved model make it possible to calculate the output parameters and efficiency, taking into account the change in the real area of the receptive surface of the PVC SSL, and, therefore, to more accurately determine the CVC.

5. 5. Results of experimental studies of the dependence of the output parameters on the real area of the receiving surface

5.5.1. Study of the dependence of the real area of the receiving surface of a solar cell on the fractal dimension

The study of the dependence of the output parameters $P_{V}, U_{N}$, $I_{N}$ on the real area $S_{R E A L}$ of the receiving surface of the PVC was carried out on the basis of a computational experiment using the engineering mathematical software MathCAD.

At the beginning of the experiment, by a computational method, for various values of the value of the real area of the receiving surface of the PVC, dependences on. Then, from the angle of inclination of its linear section, the value of the fractal dimension for the corresponding area was determined, as shown in Fig. 6.

The results are shown in the graphs in Fig. 6, where the values of the measuring scale $\alpha=\alpha=3 \ldots 6 \cdot 10^{-6} \mathrm{~m}$ were taken based on the size of the local pore $3 . .5 \mu \mathrm{m}$ with a semiconductor layer thickness $\delta=300 \mu \mathrm{m}$. From the graphs in Fig. 6, it can be seen that with a change in the value of the fractal dimension from 2.01 to 2.93 , the surface area from the initial value of $14.400 \cdot 10^{-3} \mathrm{~m}^{2}$ decreases to the real surface area equal to $14.374 \cdot 10^{-3} \mathrm{~m}^{2}$. This confirms the results of theoretical studies, on the correspondence of the value of the fractal dimension to a certain value of the area, as well as on the power-law dependence of the geometric topological surface on the value of the fractal dimension. In addition, it was determined that in the range of change in the value of the fractal dimension from 2.63 to 2.93 , the change in the value of the working area of the receiving surface does not significantly affect the output SC parameters. This is explained by the excess of the percentage of porosity (the presence of micropores and microcracks is more than $20 \%$ ) in the semiconductor layer of the SC.

Further, in the course of the experiment, a generalized dependence of the value of the real area $S_{R E A L}$ of the PVC surface on the value of the fractal dimension $d_{f}$ of the bulk structure of the PVC SSL was obtained, as shown in the graph in Fig. 7.
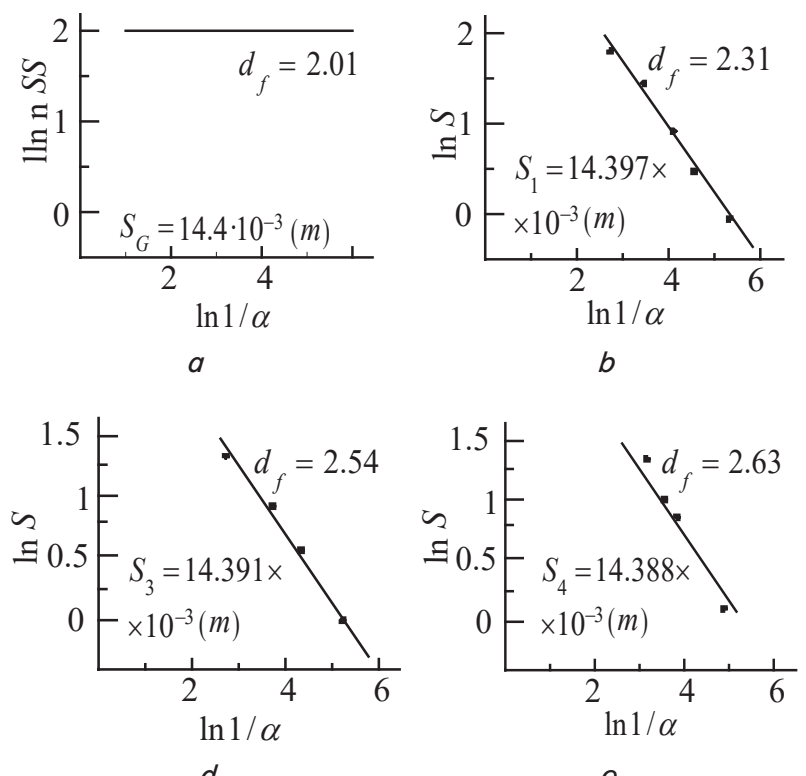

e

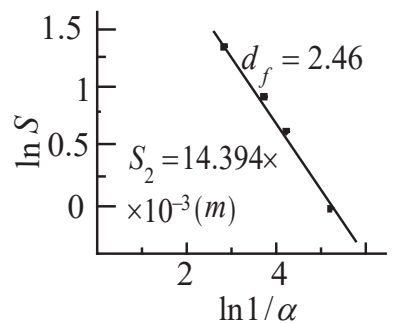

C

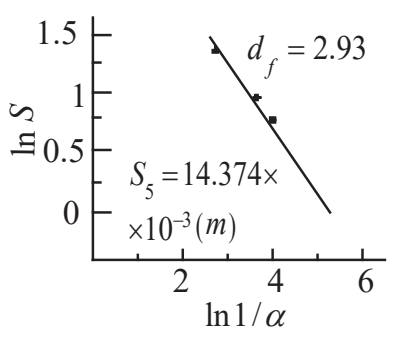

$f$
Fig. 6. Graphs of $\ln \left(S_{R E A L} / S_{G}\right)$ on $\ln (1 / \alpha)$ to determine the real areas depending on the fractal dimensions of the surface structure of the photoelectric converter: $a-$ at $d_{f}=2.01$ for $S_{G}=14.4 \cdot 10^{-3}(\mathrm{~m}) ; b-$ at $d_{f}=2.31$ for $S_{1}=14.397 \cdot 10^{-3}(\mathrm{~m}) ; c-$ at $d_{f}=2.46$ for $S_{2}=14.394 \cdot 10^{-3}$ $(\mathrm{m}) ; d-$ at $d_{f}=2.54$ for $S_{3}=14.391 \cdot 10^{-3}(\mathrm{~m}) ; e-$ at $d_{f}=2.63$ for $S_{4}=14.388 \cdot 10^{-3}(\mathrm{~m}) ; f-$ at $d_{f}=2.93$ for $S_{5}=14.374 \cdot 10^{-3}(\mathrm{~m})$ 


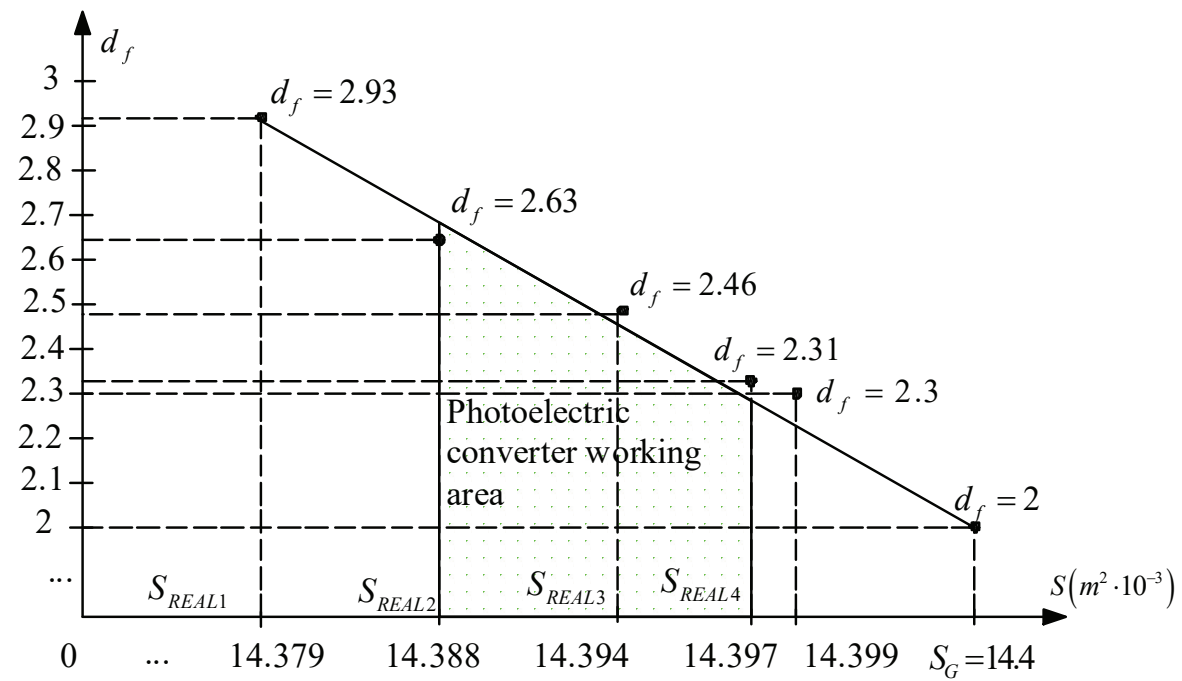

Fig. 7. Dependences of the value of the real surface area of the photoelectric converter on the value of the fractal dimension of the volumetric structure of the semiconductor layer

Fig. 7 that a change in the value of the fractal dimension $d_{f}$ in the range $2<d_{f}<2.93$ leads to a decrease in the real area $S_{R E A L}$ of the receiving surface from $14.400 \cdot 10^{-3} \mathrm{~m}^{2}$ to $14.374 \times$ $\times 10^{-3} \mathrm{~m}^{2}$. However, in the range of change in fractal dimension from 2 to 2.3 , there is practically no change in the value of the working area of the receiving surface of the SC. This effect is explained by the fact that in industrial production, it is very difficult to achieve a perfectly smooth surface, i.e. the initially perceiving surface can be characterized by a fractal dimension up to 2.3 .

\subsection{Study of the dependence of the minimum} power of a solar cell on the fractal dimension

It should be noted that the investigated surfaces with an area less than the threshold value $S_{G}<14.4 \cdot 10^{-3} \mathrm{~m}^{2}$ are non-fractal, which means that they cannot be estimated by the value of the fractal dimension $d_{f}$. In addition, when the value of the fractal dimension $d_{f}>2.63$, the obtained values of the parameters $U_{o c}, U_{N}, I_{s c}, I_{N}$ of the solar cell do not provide the minimum value of the output power $P_{\min }$, the value of which was determined during the manufacture of the solar cell. Therefore, the working range of variation of the fractal dimension $2<d_{f}<2.63$ is set, at which the value of the output power changes from $P_{\max }$ to $P_{\min }$, as shown in Fig. 8 .

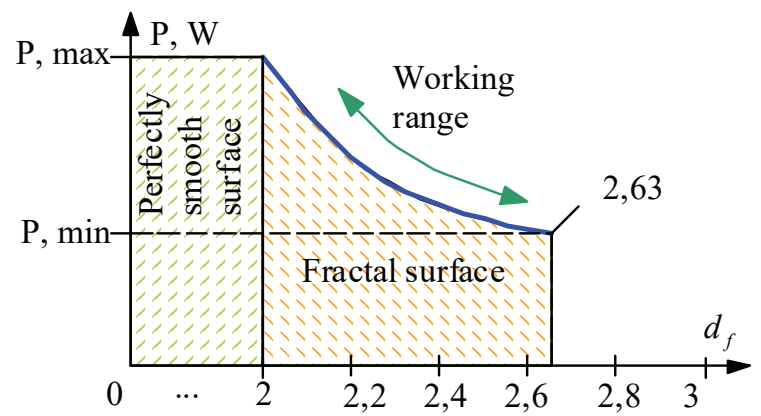

Fig. 8. Graph of the dependence of the values of the value of the output power $P_{V}$ on the change in the fractal dimension in the range $2<d_{f}<2.63$

From Fig. 8 it can be seen that with an increase in the fractal dimension to the value $d_{f}=2.63$, the output power decreases to the minimum set value.
5.5.3. Study of the dependence of the output parameters on the real working area of the receiving surface of the solar cell

According to the analytical expressions (5) and (6) of the model with the geometric area $S_{G}$ and (22), (23) of the model with real surface areas $\left(S_{R E A L}^{1} ; S_{R E A L}^{2} ; S_{R E A L}^{3} ; S_{R E A L}^{4}\right)$, the PVC CVCs were constructed using the MathCAD computer program (Fig. 9).

As the initial data, the parameters of the PVC module of the KSR150 type were used, with the passport parameters: temperature $T=25^{\circ} \mathrm{C}$; emission spectrum $A M=1.5$; surface illumination $E_{0}=1000 \mathrm{~W} / \mathrm{m}^{2}$; $K_{U}=-0.1230 \mathrm{~V} / \mathrm{K} ; K I=0.0032 \mathrm{~A} / \mathrm{K}$ and area $S_{G}=14.4 \cdot 10^{-2} \mathrm{~m}^{2}$. The estimation of the characteristic damaging surface defects, in the form of micropores and macrocracks, was carried out conventionally in the range of the measurement scale for values from 0.03 to $3 \mu \mathrm{m}$. Table 1 shows the passport and design parameters of the PVC of the KS200G module for the obtained different values of the real areas of the PVC SSL surfaces.

Table 1

Passport and design parameters of the PVC of the KS200G module at various values of real surfaces

\begin{tabular}{|c|c|c|c|c|c|c|c|c|c|}
\hline \multirow{4}{*}{$\begin{array}{c}\text { Initial } \\
\text { data }\end{array}$} & \multicolumn{9}{|c|}{ Fractal (porous, heterogeneous) } \\
\hline & \multirow{2}{*}{$\begin{array}{c}S_{G} \cdot 10^{-3} \mathrm{~m}^{2} \\
d=2\end{array}$} & \multicolumn{8}{|c|}{$S_{R E A L}\left(1 \cdot 10^{-3} \mathrm{M}^{2}\right)$} \\
\hline & & $S_{R E A L}^{1}$ & $d_{f 1}$ & $S_{R E A L}^{2}$ & $d_{f 2}$ & $S_{R E A L}^{3}$ & $d_{f 3}$ & $S_{R E A L}^{4}$ & $d_{f 4}$ \\
\hline & 14.400 & 14.397 & 2.31 & 14.394 & 2.46 & 14.391 & 2.54 & 14.388 & 2.63 \\
\hline $\begin{array}{l}I_{M P P} \\
(\mathrm{~A})\end{array}$ & 0.1409 & \multicolumn{2}{|c|}{0.1404} & \multicolumn{2}{|c|}{0.1398} & \multicolumn{2}{|c|}{0.1393} & \multicolumn{2}{|c|}{0.1387} \\
\hline $\begin{array}{c}U_{M P P} \\
(\mathrm{~V})\end{array}$ & 0.4706 & \multicolumn{2}{|c|}{0.4697} & \multicolumn{2}{|c|}{0.4694} & \multicolumn{2}{|c|}{0.4690} & \multicolumn{2}{|c|}{0.4683} \\
\hline$P_{\max }$ & 3.7037 & \multicolumn{2}{|c|}{3.7021} & \multicolumn{2}{|c|}{3.7013} & \multicolumn{2}{|c|}{3.7004} & \multicolumn{2}{|c|}{3.5911} \\
\hline $\begin{array}{l}U_{o c} \\
(\mathrm{~V})\end{array}$ & 0.6093 & \multicolumn{2}{|c|}{0.6084} & \multicolumn{2}{|c|}{0.6079} & \multicolumn{2}{|c|}{0.6072} & \multicolumn{2}{|c|}{0.6066} \\
\hline$I_{s c}(\mathrm{~A})$ & 0.1520 & \multicolumn{2}{|c|}{0.1493} & \multicolumn{2}{|c|}{0.1481} & \multicolumn{2}{|c|}{0.1464} & \multicolumn{2}{|c|}{0.1473} \\
\hline $\begin{array}{l}I_{O N} \\
(\mathrm{~A})\end{array}$ & $0.18191 \cdot 10^{-8}$ & \multicolumn{2}{|c|}{$0.1808 \cdot 10^{-8}$} & \multicolumn{2}{|c|}{$0.1805 \cdot 10^{-8}$} & \multicolumn{2}{|c|}{$0.1801 \cdot 10^{-8}$} & \multicolumn{2}{|c|}{$0.1798 \cdot 10^{-8}$} \\
\hline$I_{F}(\mathrm{~A})$ & 0.1521 & \multicolumn{2}{|c|}{0.1514} & \multicolumn{2}{|c|}{0.1507} & \multicolumn{2}{|c|}{0.1499} & \multicolumn{2}{|c|}{0.1493} \\
\hline $\begin{array}{c}R_{S} \\
(\mathrm{Ohm})\end{array}$ & 7.6927 & \multicolumn{2}{|c|}{7.6958} & \multicolumn{2}{|c|}{7.6979} & \multicolumn{2}{|c|}{7.6996} & \multicolumn{2}{|c|}{7.7018} \\
\hline $\begin{array}{c}R_{L} \\
(\mathrm{Ohm})\end{array}$ & $4.09 \cdot 10^{-3}$ & \multicolumn{2}{|c|}{$4.029 \cdot 10^{-3}$} & \multicolumn{2}{|c|}{$4.47 \cdot 10^{-3}$} & 4.69 & $10^{-3}$ & 4.81 & $10^{-3}$ \\
\hline
\end{tabular}

As can be seen from the graph in Fig. 9, the CVC curves for real areas $\left(S_{R E A L}^{1} ; S_{R E A L}^{2} ; S_{R E A L}^{3} ; S_{R E A L}^{4}\right)$ of the receiving surface differ from the curve for the geometric topological area $S_{G}$.

Calculations according to formula (24) show a decrease in the installed output power for a solar cell by $2.1 \%$ (power loss $\Delta P=0.113 \mathrm{~W}$ ), and, therefore, according to formula (25), to a decrease in the SC efficiency by $1.89 \%$. The accuracy of plotting the current-voltage characteristic of the solar cell increased by $4.2 \%$. 


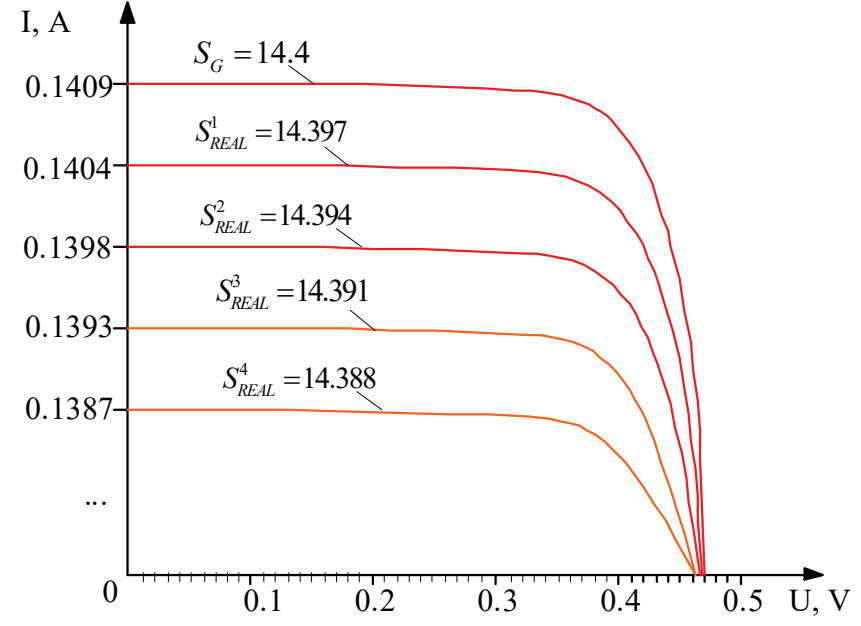

Fig. 9. Current-voltage characteristic of the photoelectric converter: for the geometric area of the topological surface $S_{G}$ and real areas $\left(S_{R E A L}^{1} ; S_{R E A L}^{2} ; S_{R E A L}^{3} ; S_{R E A L}^{4}\right)$ of the receiving surface

\section{Discussion of the results of the development of a solar cell model based on the application of the apparatus of fractal geometry}

The main feature is that the quantitative parameter of the fractal dimension is selected and used as an effective criterion for assessing the development of the micro- and macrostructure of the rough surface semiconductor layer of PVC.

The working surfaces of solar PVCs were considered to be close to ideally smooth, with minor manufacturing defects, therefore, as a rule, assumptions and limitations were introduced for them when calculating the PVC parameters. This, in turn, sometimes caused undesirable deviations from the CVC of a real PVC, which distorted the real indicators of the output power and efficiency of the PVC. One of the reasons for such deviations in the $\mathrm{CVC}$ is certain difficulties in assessing the quality of the surface relief of the PVC, and in particular the effect of damaging defects on the internal structure of the semiconductor layer of the PVC. Therefore, taking into account all the difficulties associated with determining the real characteristics of the PVC, it is proposed in the work, to improve the model of the PVC, to introduce such an additional parameter that takes into account the real area of the receiving surface of the semiconductor layer of the PVC. It is proposed to calculate this real active surface area using the apparatus of fractal geometry, both for the external and internal structure of the semiconductor layer of the PVC, based on the geometric model (18).

The developed geometric model of the receptive surface of the PVC, which is characterized by fractal properties, can be used to assess both the external and internal structure of the semiconductor layer when calculating the real area in the models of PVC. In addition, it is shown that the real area of the receiving surface of the PVC is in power-law dependence on the value of the fractal dimension, and corresponds to its certain value (Fig. 9).

The resulting improved model of the PVC allows, on the basis of analytical expressions (23) and (24), to more accurately construct the CVC, and to determine the value of the real output power and efficiency, for the real area of the absorbing surface of the PVC. Due to the proposed
PVC model, it is possible to build CVC and with parameter accuracy sufficient for engineering calculations, when assembling solar modules, panels, batteries and solar power plants in general.

The main result of this study is to determine the degree of influence of the real area of the receiving surface with damaging defects on the change in the values of the input and output parameters when calculating them in models of solar photovoltaic converters.

The proposed method of the theory of fractal geometry can be used to study the rate of development of defects in the form of macro- and microcracks under the conditions of the formation of cluster-cluster aggregations in the PVC SSL structure. To do this, it is necessary to carry out additional research and calculations of the cluster formation time, which in the future will be taken into account when changing the useful area in the tasks of predicting the volumes of electricity generation by a photovoltaic station.

In addition, with the continuation of further research, it is planned to conduct full-scale physical experiments, on the created laboratory facility, to carry out measurements in the operating conditions of the solar cell. This will make it possible to obtain accurate CVC, both for ideal conditions and for operating conditions during the operation of the solar cell.

As a disadvantage, it should be noted that data on the geometry of the micro- and macrostructure of the surface are obtained using a scanning tunneling microscope, for the calibration of which, as a rule, test surfaces with known relief parameters are used. This is an expensive and time-consuming process, therefore, in further research, to determine the value of the fractal dimension in the structure of the semiconductor layer of the PVC, it is necessary to apply the skin effect method.

\section{Conclusions}

1. The analysis of external and internal factors causing damaging defects on the sensing surface of the solar cell was carried out, which showed their influence on:

- decrease in the value of output power and efficiency during long-term operation;

- change in the passport characteristics provided by the manufacturer and, as a consequence, a discrepancy with the real CVC and VWC, due to a certain degree of approximation, taking into account the assumptions about the state of the real surface of the PVC;

- change in the degree of filling of the CVC for the established efficiency.

In this regard, a new approach has been proposed for studying physical processes in the structure of the receiving surface of a PVC, based on the apparatus of fractal geometry, which takes into account damaging defects when calculating the nominal power.

2. A geometric model of the surface of the solar cell has been developed, which takes into account the physical processes when the structure of the damaging surface of the semiconductor layer changes with the use of the apparatus of fractal geometry.

The geometrical model of the relief of the receiving surface takes into account in the structure of the semiconductor layer of the PVC, the presence of local inhomogeneities, micropores and macrocracks, which affect the size of the working area of 
the PVC. It is shown that such structures have fractal properties and are characterized by a quantitative fractal dimension. Based on the use of the apparatus of fractal geometry, the real area of the receptive active surface of the PVC was determined, which is in power-law dependence on the fractal dimension and corresponds to its certain value. It is shown that a change in the value of the fractal dimension in the range from 2 to 2.93 leads to a decrease in the real area of the receiving surface from $14.400 \cdot 10^{-3} \mathrm{~m}^{2}$ to $14.374 \cdot 10^{-3} \mathrm{~m}^{2}$.

3 . The choice of an effective parameter has been substantiated for assessing the qualitative state of changes in the structure of the receiving surface of the semiconductor layer by a quantitative value - fractal dimension.

The choice of the parameter of fractal dimension has been theoretically and experimentally substantiated as an effective criterion for assessing the development of the micro- and macrostructure of the receptive surface layer of PVC. The use of the parameter of fractal dimension is proposed in relation to the problems of calculating the value of the real output power and the efficiency of PVC. The advantage is shown of using the fractal geometry method for constructing fractal surfaces over classical models of nonsmooth shapes, both for a complete description of the geometry of the surface layer of a PVC, and for further calculation of the parameters of a PVC. The construction of a surface model using fractal principles is substantiated theoretically, experimentally confirmed and underlies the study of the influence of the geometry of the micro- and macrostructure of the surface on the physical properties of the investigated materials of the surface layer of PVC. The results of the analysis show that the method for studying the development of the PVC surface structure, based on the theory of fractals, makes it possible to assess the characteristic damaging defects lying in the range of values from 0.03 to $3 \mu \mathrm{m}$.

4. The structure of the model is proposed, taking into account the micro- and macrostructure of the receiving surface of the semiconductor layer, which takes into account the working area of the real micro and macrostructure of the surface layer of the semiconductor layer, using a calculator of fractal geometry. The resulting model makes it possible to calculate the output parameters taking into account the working area of the real receiving surface and to increase the accuracy, stability of the CVC and to determine the real value of the output power and the efficiency of the PVC. Improved analytical expressions for calculating the output parameters have been received and proposed, taking into account the real geometric structural changes in the surface layer of PVC, in the presence of damaging defects. The obtained analytical expressions of the improved PVC model also made it possible to calculate and clarify the input parameters (short-circuit current, open circuit voltage, maximum output power), which are different from the factory-set values. It is shown that the installed output power for the PVC is reduced by $2.1 \%$ (power loss $\Delta P=0.113 \mathrm{~W}$ ), and, therefore, this leads to a decrease in the PVC efficiency by $1.89 \%$. The accuracy of plotting the CVC of the solar cell increased by $4.2 \%$.

5. A computational experiment was carried out to construct the CVC taking into account the real area of the actual receiving surface, which confirmed the influence of the changed geometric characteristics of the surface on the output parameters of the solar cell.

The created improved model can be practically used to control the input and output parameters of PVC at the stage of assembly, rejection of solar modules, panels, batteries and the whole of solar stations, according to the corresponding required characteristics.

A practical computational experiment confirmed the influence of the geometric characteristics of the surface on the output parameters of the PVC, based on the use of fractal geometry methods. The results of theoretical studies on the correspondence of the value of the fractal dimension to a certain value of the area, as well as the power-law dependence of the geometric topological surface on the value of the fractal dimension have been confirmed. It is shown that with an increase in roughness and porosity, due to damaging defects, a decrease in the real area of the surface semiconductor layer is observed, with a change in the fractal dimension in the range from 2.31 to 2.63. This, in turn, affects the magnitude of the load current and voltage, which leads to a distortion of the CVC and a decrease in the output power by $1.49 . .2 .1 \%$ and a decrease in the efficiency from 2 to $3 \%$.

It has been experimentally confirmed that fractal models make it possible to simplify and reduce the cost of calculating such physical quantities as the output power and the efficiency of PVCs, due to the stage of direct investigation of the geometric characteristics of a real surface.

The practical significance of the improved model of solar cells lies in the usefulness and expediency of modeling the receptive surface of solar cells, to increase the efficiency of their application in various (ground, space) photovoltaic systems (PVS). Further development of the obtained analytical expressions of the improved model makes it possible to compare the CVC and VWC of a number of solar modules, panels, and batteries. This, in turn, makes it possible to develop practical recommendations for the construction of photovoltaic systems for various purposes. In addition, the above provisions make it possible to improve the qualitative results of developments in the creation of new samples and modernization of existing photovoltaic systems. The practical provisions contained in the work are useful in calculating the energy parameters of photovoltaic systems, working out algorithms for capturing the maximum power point, developing specific proposals for the use of solar modules, panels, batteries. SC simulation allows matching the dynamic operating modes of the converters included in the photovoltaic systems. The practical implementation of the obtained improved model is a theoretical basis and a prepared mathematical tool for further scientific research on the characteristics of solar modules, panels, batteries and processing their results.

References

1. Kurtz, S., Haegel, N., Sinton, R., Margolis, R. (2017). A new era for solar. Nature Photonics, 11 (1), 3-5. doi: http://doi.org/10.1038/ nphoton.2016.232

2. Ibrahim, A. (2011). Effect of Shadow and Dust on the Performance of Silicon Solar Cell. Journal of Basic and Applied Sciences Research, 1 (3), 222-230. Available at: https://www.researchgate.net/profile/A-Ibrahim/publication/267971484_Effect_of_ Shadow_and_Dust_on_the_Performance_of_Silicon_Solar_Cell/links/54db59660cf233119bc5ef7d/Effect-of-Shadow-andDust-on-the-Performance-of-Silicon-Solar-Cell.pdf 
3. Alharbi, F. H., Kais, S. (2015). Theoretical limits of photovoltaics efficiency and possible improvements by intuitive approaches learned from photosynthesis and quantum coherence. Renewable and Sustainable Energy Reviews, 43, 1073-1089. doi: http:// doi.org/10.1016/j.rser.2014.11.101

4. Kozyukov, D. A., TSygankov, B. K. (2015). Modelirovanie kharakteristik fotoelektricheskikh moduley v MATLAB/Simulink. Nauchniy zhurnal KubGAU, 112 (8), 1-16. Available at: https:/cyberleninka.ru/article/n/modelirovanie-harakteristikfotoelektricheskih-moduley-v-matlab-simulink

5. Siddiqui, M. U., Abido, M. (2013). Parameter estimation for five- and seven-parameter photovoltaic electrical models using evolutionary algorithms. Applied Soft Computing, 13 (12), 4608-4621. doi: http://doi.org/10.1016/j.asoc.2013.07.005

6. Ruby, N., Jayabarathi, R. (2017). Predicting the Power Output of a Grid-Connected Solar Panel Using Multi-Input Support Vector Regression. Procedia Computer Science, 115, 723-730. doi: http://doi.org/10.1016/j.procs.2017.09.143

7. Salmi, T., Bouzguenda, M., Gastli, A., Masmoudi, A. (2012). MATLAB/Simulink Modelling of Solar Photovoltaic Cell. International Journal of Renewable Energy Research, 2 (2), 213-218. Available at: https://www.researchgate.net/publication/258913169 MATLABSimulink_Based_Modelling_of_Solar_Photovoltaic_Cell

8. Malik, K., Bhatti, B. A., Kamran, F. (2016). An approach to predict output of PV panels using weather corrected global irradiance. IEEE International Conference on Intelligent Systems Engineering, 111-117. doi: http://doi.org/10.1109/intelse.2016.7475171

9. Ivanchura, V. I., Chubar, A. V., Post, S. S. (2012). Energy Prototypes of Units in Autonomous Power Supply Systems. Zhurnal SFU. Tekhnika i tekhnologii, 2, 179-190. Available at: https://cyberleninka.ru/article/n/energeticheskie-modeli-elementovavtonomnyh-sistem-elektropitaniya/viewer

10. Nguyen, X. H., Nguyen, M. P. (2015). Mathematical modeling of photovoltaic cell/module/arrays with tags in MATLAB/Simulink. Environmental Systems Research, 4 (24), 7-22. doi: http://doi.org/10.1186/s40068-015-0047-9

11. Wang, Z., He, L., Cheng, X., He, J. (2014). Method for short-term photovoltaic generation power prediction base on weather patterns. IEEE China International Conference on Electricity Distribution, 213-215. doi: http://doi.org/10.1109/ciced.2014.6991696

12. Elbaset, A. A., Ali, H., Abd-El Sattar, M. (2014). Novel seven-parameter model for photovoltaic modules. Solar Energy Materials and Solar Cells, 130, 442-455. doi: https//doi.org/10.1016/j.solmat.2014.07.016

13. Ahmad, A. (2013). A simple method to extract the parameters of the single-diode model of a PV system. Turkish Journal of Physics, 37, 121-131. Available at: https://www.academia.edu/7441877/A_simple_method_to_extract_the_parameters_of_the_single_ diode_model_of_a_PV_system

14. Koval, O. S., Tivanov, M. S. (2012). Opredelenie parametrov solnechnogo elementa iz ego volt-ampernoy kharakteristiki. Vestnik BGU, 1 (2), 39-44. Available at: https://elib.bsu.by/bitstream/123456789/44192/1/39-44.pdf

15. Feder, E. (2014). Fraktaly. Moscow: URSS: Lenand, 256. Available at: http://www.prometeus.nsc.ru/acquisitions/15-04-14/ cont01.ssi

16. Balkhanov, V. K. (2013). Osnovy fraktalnoy geometrii i fraktalnogo ischisleniya. Ulan-Ude: Izd-vo Buryatskogo gosuniversiteta, 224. Available at: http://ipms.bscnet.ru/publications/src/2013/FractGeomet.pdf

17. Budanov, P., Brovko, K., Cherniuk, A., Pantielieieva, I., Oliynyk, Y., Shmatko, N., Vasyuchenko, P. (2018). Improvement of safety of autonomous electrical installations by implementing a method for calculating the electrolytic grounding electrodes parameters. Eastern-European Journal of Enterprise Technologies, 5 (5 (95)), 20-28. doi: http://doi.org/10.15587/1729-4061.2018.144925

18. Mandelbrot, B. (2010). Fraktalnaya geometriya prirody. Izhevskiy institut kompyuternykh issledovaniy, NITS «Regulyarnaya i khaoticheskaya dinamika», 656 .

19. Zinovev, V. V., Beltyukov, A. P., Bartenev, O. A. (2016). Matematicheskaya model fotoelektricheskogo preobrazovatelya s ispolzovaniem W-funktsii Lamberta. Izvestiya Instituta matematiki i informatiki, 2 (48), 22-30.

20. Slipchenko, N. I. (2011). Eksperimentalnye issledovaniya kharakteristik solnechnoy paneli KV 150/24(12) v zimnikh usloviyakh. Vestnik Nats. tekhn. un-ta "KHPI". Temat. vyp.: Novye resheniya v sovremennykh tekhnologiyakh, 24, 86-92. Available at: http:// repository.kpi.kharkov.ua/handle/KhPI-Press/12877

21. Said, S., Massoud, A., Benammar, M., Ahmed, S. (2012). A matlab/simulink based photovoltaic array model employing simpowersystems toolbox. Journal of Energy and Power Engineering, 6, 1965-1975. Available at: https://www.researchgate.net/ publication/285027675_A_matlabsimulink_based_photovoltaic_array_model_employing_simpowersystems_toolbox

22. Savrasov, F. V., Kovalev, I. K. (2012). Issledovanie effektivnosti raboty solnechnoy batarei v polevykh usloviyakh. Izvestiya Tomskogo politekhnicheskogo universiteta, 321 (4), 165-168. Available at: http://earchive.tpu.ru/handle/11683/4482

23. Lunin, L. S., Paschenko, A. S. (2011). Modelirovanie i issledovanie kharakteristik fotoelektricheskikh preobrazovateley na osnove GaAs i GaSb. ZHurnal tekhnicheskoy fiziki, 81, 71-76. Available at: https://elibrary.ru/item.asp?id=20325216

24. Cotfas, D. T., Cotfas, P. A., Kaplanis, S. (2013). Methods to determine the dc parameters of solar cells: A critical review. Renewable and Sustainable Energy Reviews, 28, 588-596. doi: http://doi.org/10.1016/j.rser.2013.08.017

25. Rudenko, D. V., Vasyuchenko, P. V. (2019). Modeling of physical processes of the solar photovoltaic. Vcheni zapysky Tavriiskoho natsionalnoho universytetu im. V. I. Vernadskoho. Seriia: Tekhnichni nauky, 30 (69), 42-47.

26. Kolosov, R. V. (2019). Modelling of solar panels. Intellektualnaya elektrotekhnika, 2 (6), 85-93.

27. Laudani, A., Riganti Fulginei, F., Salvini, A. (2014). High performing extraction procedure for the one-diode model of a photovoltaic panel from experimental I-V curves by using reduced forms. Solar Energy, 103, 316-326. doi: http://doi.org/10.1016/ j.solener.2014.02.014 
28. Lineykin, S., Averbukh, M., Kuperman, A. (2014). An improved approach to extract the single-diode equivalent circuit parameters of a photovoltaic cell/panel. Renewable and Sustainable Energy Reviews, 30, 282-289. doi: http://doi.org/10.1016/j.rser.2013.10.015

29. Dongue, S. B., Njomo, D., Tamba, J. G., Ebengai, L. (2012). Modeling of Electrical Response of Illuminated Crystalline Photovoltaic Modules Using Four- and Five-Parameter Models. International Journal of Emerging Technology and Advanced Engineering, 2, 612-619.

30. Cubas, J., Pindado, S., Victoria, M. (2014). On the analytical approach for modeling photovoltaic systems behavior. Journal of Power Sources, 247, 467-474. doi: http://doi.org/10.1016/j.jpowsour.2013.09.008

31. Peng, L., Sun, Y., Meng, Z., Wang, Y., Xu, Y. (2013). A new method for determining the characteristics of solar cells. Journal of Power Sources, 227, 131-136. doi: http://doi.org/10.1016/j.jpowsour.2012.07.061

32. Orioli, A., Di Gangi, A. (2013). A procedure to calculate the five-parameter model of crystalline silicon photovoltaic modules on the basis of the tabular performance data. Applied Energy, 102, 1160-1177. doi: http://doi.org/10.1016/j.apenergy.2012.06.036

33. Seifi, M., Che Soh, A. Bt., Izzrib, N., Wahab Abd., Khair, M., Hassan, B. (2013). A Comparative Study of PV Models in Matlab/ Simulink. International Scholarly and Scientific Research \& Innovation, 7 (2), 97-102.

34. Cubas, J., Pindado, S., de Manuel, C. (2014). Explicit Expressions for Solar Panel Equivalent Circuit Parameters Based on Analytical Formulation and the Lambert W-Function. Energies, 7 (7), 4098-4115. doi: http://doi.org/10.3390/en7074098

35. Cucchiella, F., D’Adamo, I., Gastaldi, M. (2016). A profitability assessment of small-scale photovoltaic systems in an electricity market without subsidies. Energy Conversion and Management, 129, 62-74. doi: http://doi.org/10.1016/j.enconman.2016.09.075

36. Villalva, M. G., Gazoli, J. R., Filho, E. R. (2009). Comprehensive Approach to Modeling and Simulation of Photovoltaic Arrays. IEEE Transactions on Power Electronics, 24 (5), 1198-1208. doi: http://doi.org/10.1109/tpel.2009.2013862

37. Stanly, L. S., Divya, R., Nair, M. G. (2015). Grid connected solar photovoltaic system with Shunt Active Filtering capability under transient load conditions. IEEE International Conference on Advancements in Power and Energy, 345-350. doi: http://doi.org/ 10.1109/tapenergy.2015.7229643

38. Salmi, T., Bouzguenda, M., Gastli, A., Masmoundi, A. (2012). MATLAB/Simulink Based Modelling of Solar Photovoltaic Cell. International Journal of Renewable energy researcg, 2, 213-218.

39. Patil Sahebrao, N., Prasad, R. C. (2014). Design and simulation of MPPT algorithm for solar energy system using Simulink model. International Journal of Research in Engineering and Applied Sciences, 2 (1), 37-40. Available at: https://www.semanticscholar.org/ paper/DESIGN-AND-SIMULATION-OF-MPPT-ALGORITHM-FOR-SOLAR-Sahebrao-Prasad/69aec92f9308bc20f0771649c81f8 $54 \mathrm{e} 8907 \mathrm{adba}$

40. Surya Kumari, J., Sai Babu, Ch. (2012). Mathematical Modelling and Simulation of Photovoltaic Cell Using MATLAB/Simulink Environment and PLECS Blockset. International Journal of Electrical and Computer Engineering, 2 (1), 26-34. doi: http://doi.org/ 10.11591/ijece.v2i1.117 